\title{
Self-reported psychotic symptoms in the general
}

\section{population}

\author{
Results from the longitudinal study of the British National \\ Psychiatric Morbidity Survey
}

NICOLA J. WILES, STANLEY ZAMMIT, PAUL BEBBINGTON,
NICOLA SINGLETON, HOWARD MELTZER and GLYN LEWIS

\begin{abstract}
Background Scarce longitudinal data exist on the occurrence of psychotic

symptoms in the general population.
\end{abstract}

Aims To estimate the incidence of, and risk factors for, self-reported psychotic symptoms in Great Britain.

\section{Method Data from the 18 -month}

follow-up of a national survey were used. Incident cases were those who endorsed one or more items on the Psychosis

Screening Questionnaire at follow-up, but not at baseline. The association between factors recorded at baseline and incident self-reported symptoms was examined.

Results At follow-up, $4.4 \%$ of the general population reported incident psychotic symptoms. Six factors were independently associated with incident symptoms: living in a rural area; having a small primary support group; more adverse life events; smoking tobacco; neurotic symptoms; and engaging in a harmful pattern of drinking.

\section{Conclusions A small but not} insignificant percentage of the population of Great Britain reported incident psychotic symptoms over 18 months. The risk factors for psychotic symptoms showed some similarities with risk factors for schizophrenia, but there were also some striking differences. The relationship between such risk factors and the factors that perpetuate psychotic symptoms remains to be ascertained.

Declaration of interest None. Funding detailed in Acknowledgements.
There is increasing evidence that established psychotic symptoms may be present in milder forms in the general population (van Os et al, 2000; van Os \& Verdoux, 2002), with population prevalence estimates ranging from $1 \%$ (Eaton et al, 1991 ) to $17.5 \%$ (van Os et al, 2000). Such variation can be explained by methodological differences in the instruments and thresholds used to define psychotic symptoms, the period of recall, whether estimates are based on single specific symptoms or a range of symptoms, and differences in the characteristics of the populations studied. A 1-year incidence of $4.6 \%$ was reported for hallucinations in the Epidemiologic Catchment Area programme (Tien, 1991), but there are few other data. The identification of potential aetiological risk factors has been limited by the use of cross-sectional data (Verdoux et al, 1998; van Os et al, 2000, 2001; Johns et al, 2002, 2004; Olfson et al, 2002; King et al, 2005), with a few notable exceptions (Tien, 1991; Janssen et al, 2003). An excess of apparent hallucinations has been reported in women (Tien, 1991), but longitudinal studies have primarily focused on the aetiological role of cannabis (Arseneault et al, 2002; van Os et al, 2002; Fergusson et al, 2003).

The 18-month follow-up of participants in the British National Survey of Psychiatric Morbidity provides a rare opportunity to examine the incidence of, and risk factors for, self-reported psychotic symptoms using prospective longitudinal data.

\section{METHOD}

\section{National Psychiatric Morbidity Survey}

Full details of the 18-month follow-up of the Office for National Statistics (ONS) 2000 Psychiatric Morbidity Survey are available elsewhere (Singleton $e t$ al, 2001; Singleton \& Lewis, 2003). Briefly, a nationally representative sample of 8580 adults aged 16-74 years living in private households in Great Britain were interviewed by lay interviewers in 2000 (Singleton et al, 2001) and classified according to their score on the Clinical Interview Schedule - Revised (CIS-R; Lewis et al, 1992; Lewis, 1994). All participants identified as having a mental disorder (CIS-R score $\geqslant 12$ ) at the time of the cross-sectional survey and those with sub-threshold neurotic symptoms (CIS-R score 6-11) were eligible for follow-up, as were a random $20 \%$ of those without a mental disorder. Using the above criteria, 3536 persons were selected for follow-up, the majority of whom $(n=3045)$ were successfully contacted. More than three-quarters $(79 \%, n=2413)$ completed the follow-up interview, $17 \%$ $(n=503)$ refused, and contact was not made with 129 (4\%). The Multicentre Research Ethics Committees in England granted ethical approval for the study.

\section{Measurement of psychotic symptoms}

Positive psychotic symptoms comprise anomalous experiences (hallucinations, thought insertion) and abnormal beliefs (delusions). Classically, these are identified by a process of cross-examination, whereby the definition of the symptoms is matched with someone's experience (Brugha et al, 1999), but in-depth psychiatric interviews are impractical for large population surveys. Lay interviews are a less rigorous method of establishing psychotic symptoms, but there is evidence that people who endorse items on the Psychosis Screening Questionnaire (PSQ; Bebbington \& Nayani, 1995) are similar to those who are actually diagnosed using a standardised clinical instrument (Johns et al, 2002), suggesting that there are continuities.

In our study the presence of psychotic symptoms was elicited (at baseline and follow-up) using the PSQ, which includes five sections relating to hypomania, thought insertion, paranoia, strange experiences and hallucinations. Each section begins with an introductory question, which, if the participant answers positively, is followed by one or two key questions. A positive response to a key question would normally mean that subsequent sections of the questionnaire are omitted, as those individuals would be regarded as 'screen positive' and would undergo a clinical assessment to establish the presence (or 
absence) of psychosis. However, for the purposes of the ONS survey, each of the five introductory PSQ questions was asked (with key questions). In the initial survey, the reference period for reporting symptoms was the 12 months prior to interview. For the follow-up survey, this was amended to the entire period since the previous interview (approximately 18 months).

\section{Baseline assessment of psychosis}

A two-stage process (Meltzer et al, 1994; Singleton et al, 1998) was used to exclude individuals with a psychotic disorder at baseline from the data-set. Participants were regarded as screening positive for a psychotic disorder if they self-reported a diagnosis or had symptoms suggestive of a psychotic disorder (e.g. hallucinations), were in receipt of antipsychotic medication, had been previously admitted to a psychiatric hospital or had responded positively to the question about auditory hallucinations on the PSQ. These individuals, and a sample of those who were screen negative, were selected for clinical interview. Diagnoses of psychotic disorder according to ICD-10 criteria (World Health Organization, 1993) were obtained using the computerised version 2.1 of the Schedules for Clinical Assessment in Neuropsychiatry (SCAN; Wing et al, 1990). People who refused to take part in the second interview or could not be contacted were assigned a diagnosis of probable psychotic disorder if they met at least two of the four psychosis screening criteria (Singleton et al, 1998).

\section{Statistical analysis}

All analyses were conducted in Stata version 8 for Windows using the svy commands. Probability weights were used to account for the stratified sampling procedure and non-response. Full details of the weighting procedure are provided in the ONS report (Singleton \& Lewis, 2003).

\section{Occurrence of self-reported psychotic symptoms}

The prevalence of psychotic symptoms at baseline was estimated, together with the persistence of such symptoms.

\section{Incident self-reported psychotic symptoms and risk factor identification}

The emergence of incident psychotic symptoms (thought insertion, paranoia, strange experiences and hallucinations) between the baseline and follow-up surveys, at the level of the introductory and key questions, was ascertained for the entire cohort and stratified by gender. The term 'incident symptoms' was used to describe 'new onset' symptoms that occurred between baseline and follow-up. It is possible that such symptoms will not represent their first-ever occurrence, but a true measure of incident psychotic symptoms is difficult to obtain in adults. We assume that these errors will primarily lead to random misclassification.

Subsequent analyses examined risk factors for incident psychotic symptoms at follow-up. A positive response to the first key question for any of the four sections covering thought insertion, paranoia, strange experiences and hallucinations was defined as an incident psychotic symptom. Based on the epidemiology of schizophrenia, the following variables, recorded at baseline, were examined for their association with self-reported psychotic symptoms at follow-up: age; gender; baseline CIS-R score; marital status (married, cohabiting, single, widowed, divorced or separated); area type (interviewer rating of urban, semi-rural or rural); IQ score, measured using the National Adult Reading Test (Nelson, 1982); size of primary support group, a measure of the individual's social network based on the number of close friends and relatives: $0-3,4-8$ or $\geqslant 9$ (Brugha et al, 1987, 1993); number of life events, using a list of 18 items (Singleton et al, 1998) covering issues such as relationship difficulties, bereavement, illness, employment and financial problems $(0-1,2,3,4,5$ or $\geqslant 6)$; current smoking status; alcohol use, measured using the Alcohol Use Disorders Identification Test score 0-40 (AUDIT; Saunders et al, 1993); and cannabis use (not used in past year, used in past year but no report of dependency, dependent on cannabis). Dependency on cannabis was based on a positive response to one of five questions (daily use for 2 or more weeks, selfreported dependence, inability to cut down, need to use larger quantities to get an effect, or symptoms of withdrawal).

In addition, a number of socioeconomic indicators were examined: highest educational qualification (degree; teaching, Higher National Diploma or nursing qualification; A-level; General Certificate of Secondary Education or equivalent; or no qualifications), employment status (working full-time; working part-time; unemployed; long-term sick or disabled; other economically inactive), social class (I-V), using the 1991 Registrar General's Standard Occupational Classification (Office for Population Censuses and Surveys, 1991), accommodation tenure (owned outright; owned with mortgage; rented from local authority or housing association; or rented from other source) and weekly gross income $(<£ 100, £ 100-199, \quad £ 200-299$, $£ 300-399$ or $\geqslant £ 400$ ).

Logistic regression was used to examine the association between baseline variables and the onset of psychotic symptoms at follow-up. Univariable associations (in terms of odds ratios) and their $95 \%$ confidence intervals are reported. Given the rarity of the outcome, these may be interpreted as rate ratios (Rothman \& Greenland, 1998). All variables significant at $P \leqslant 0.20$ in the univariable model were entered into a multivariable model to permit identification of independent associations. Age, gender, baseline CIS-R score and use of psychotropic drugs or receipt of therapy were included in the model, which was simplified using the likelihood ratio test (Hosmer \& Lemeshow, 1989). All variables significant at $P<0.10$ were retained. Previously excluded variables (univariable, $P>0.20$ ) were added to the multivariable model to determine whether they contributed significantly; any that became significant at $P<0.10$ were retained.

\section{Data-set}

In total, 2406 participants completed the baseline and follow-up surveys. Of these, 3 individuals with missing data on psychotic symptoms and 24 individuals with psychotic disorder at baseline (SCAN or 'probable' diagnoses) were excluded from all analyses. People who reported psychotic symptoms at baseline (thought insertion, paranoia, strange experiences or hallucinations; $n=414$ ) were excluded from analyses examining the risk factors for incident symptoms. Of the remaining 1965 persons, 1795 (91\%) had data available on the specified predictors.

\section{RESULTS}

\section{Occurrence of self-reported psychotic symptoms}

At baseline, 414 individuals (weighted estimate $10.9 \%$, 95\% CI 9.5-12.4) answered positively at least one of the four key questions (first level) on thought insertion, paranoia, strange experiences and 


\section{DISCUSSION}

This study presents the first data on the incidence of, and risk factors for, selfreported psychotic symptoms in the population of Great Britain. Four per cent of the population reported incident symptoms at follow-up. Individuals living in rural areas, those who had a small primary support group (few close friends or relatives) and those who smoked tobacco or drank in a harmful manner had a two to three times greater risk of incident psychotic symptoms. The number of adverse life events and CIS-R score recorded at baseline were also strongly associated with the onset of psychotic symptoms. The effect of each of these six factors was independent. In addition, there was a trend for women and those aged 65 years and over to be less likely to report incident symptoms at follow-up, although this did not reach statistical significance.

\section{Comparison with the results of previous studies}

In cross-sectional analyses, women, younger individuals, residents of urban areas, those who had never married, those with lower levels of income or lower IQ, the less educated, the unemployed, those dependent on drugs or alcohol, those who had experienced more adverse life events and those with neurotic symptoms were more likely to report psychotic symptoms (van Os et al, 2000; Olfson et al, 2002; Johns et al, 2004). It is difficult to disentangle the temporal nature of such cross-sectional associations. Some findings may be due to reverse causality, whereas other factors may be associated with chronicity rather than symptom onset. Cannabis use is the only factor to have consistently been linked with psychotic symptoms in previous longitudinal studies (Arseneault et al, 2002; van Os et al, 2002; Fergusson et al, 2003). Little else is known about the aetiology of psychotic symptoms.

In common with earlier cross-sectional findings from the British National Psychiatric Morbidity Survey (Johns et al, 2004), we observed an association between the number of adverse life events, psychiatric morbidity (CIS-R score), alcohol dependency and self-reported psychotic symptoms. We were unable to explore the previously reported variation by ethnic group (Johns et al, 2002; King et al, 2005) given the ful drinking (AUDIT score $\geqslant 16$ ) also had an increased risk of incident psychotic cident psychotic symptoms, although the confidence interval was wide. The associations between IQ score and marital status and incident self-reported psychotic symptoms were weak (Table 4). Using a more stringent definition to define psychotic symptoms (positive response to at least one of the highest key questions) did not alter the conclusions (data not shown). 
Table 2 Cumulative incidence of self-reported psychotic symptoms between baseline and I8-month follow-up surveys

\begin{tabular}{|c|c|c|c|c|c|c|c|c|c|}
\hline \multirow[t]{3}{*}{ Psychosis Screening Questionnaire items' } & \multicolumn{9}{|c|}{ Cumulative incidence of self-reported psychotic symptoms (weighted) } \\
\hline & \multicolumn{3}{|c|}{ Total } & \multicolumn{3}{|c|}{ Men } & \multicolumn{3}{|c|}{ Women } \\
\hline & $n$ & $\%$ & $95 \% \mathrm{Cl}$ & $n$ & $\%$ & $95 \% \mathrm{Cl}$ & $n$ & $\%$ & $95 \% \mathrm{Cl}$ \\
\hline \multicolumn{10}{|l|}{ Thought insertion } \\
\hline \multicolumn{10}{|l|}{ Introductory question } \\
\hline $\begin{array}{l}\text { Have you ever felt that your thoughts were directly inter- } \\
\text { fered with or controlled by some outside force or person? }\end{array}$ & 94 & 3.2 & $2.3-4.1$ & 39 & 3.0 & I.7-4.2 & 55 & 3.4 & $2.3-4.5$ \\
\hline \multicolumn{10}{|l|}{ First key question } \\
\hline $\begin{array}{l}\text { Did this come about in a way that many people would find } \\
\text { it hard to believe, e.g. through telepathy? }\end{array}$ & 9 & 0.40 & $0.07-0.73$ & 5 & 0.52 & $0-I . I$ & 4 & 0.28 & $0-0.56$ \\
\hline \multicolumn{10}{|l|}{ Paranoia } \\
\hline $\begin{array}{l}\text { Have there been times when you felt that people were } \\
\text { against you? }\end{array}$ & 313 & 10.7 & $9.1-12.4$ & 143 & 10.7 & $8.1-13.3$ & 170 & 10.8 & $8.8-12.8$ \\
\hline \multicolumn{10}{|l|}{ First key question } \\
\hline $\begin{array}{l}\text { Have there been times when you felt that people were } \\
\text { deliberately acting to harm you or your interests? }\end{array}$ & 100 & 3.3 & $2.3-4.3$ & 50 & 3.9 & $2.3-5.5$ & 50 & 2.7 & I.8-3.7 \\
\hline \multicolumn{10}{|l|}{ Second key question } \\
\hline $\begin{array}{l}\text { Have there been times when you felt that a group of people } \\
\text { was plotting to cause you serious injury or harm? }\end{array}$ & 16 & 0.42 & $0.15-0.68$ & 7 & 0.47 & $0.03-0.91$ & 9 & 0.36 & $0.07-0.65$ \\
\hline \multicolumn{10}{|l|}{ Strange experiences } \\
\hline \multicolumn{10}{|l|}{ Introductory question } \\
\hline $\begin{array}{l}\text { Have there been times when you felt that something strange } \\
\text { was going on? }\end{array}$ & 130 & 3.9 & $2.9-4.8$ & 58 & 3.6 & $2.5-4.8$ & 72 & 4.1 & $2.6-5.5$ \\
\hline \multicolumn{10}{|l|}{ First key question } \\
\hline \multicolumn{10}{|l|}{ Hallucinations } \\
\hline \multicolumn{10}{|l|}{ Introductory question } \\
\hline $\begin{array}{l}\text { Have there been times when you heard or saw things that } \\
\text { other people couldn't? }\end{array}$ & 53 & 1.7 & $0.8-2.5$ & 16 & 0.9 & $0.39-1.3$ & 37 & 2.5 & $0.8-4.1$ \\
\hline \multicolumn{10}{|l|}{ First key question } \\
\hline $\begin{array}{l}\text { Did you at any time hear voices saying quite a few words } \\
\text { or sentences when there was no one around who might } \\
\text { account for it? }\end{array}$ & 9 & 0.19 & $0.05-0.32$ & 3 & 0.14 & $0-0.31$ & 6 & 0.23 & $0.02-0.45$ \\
\hline \multicolumn{10}{|l|}{ Any psychotic symptom (excluding mania) } \\
\hline Yes to any introductory question & 433 & 14.8 & $12.8-16.8$ & 188 & 14.0 & $11.1-16.9$ & 245 & 15.6 & $13.0-18.2$ \\
\hline Yes to first key question & 134 & 4.4 & $3.3-5.6$ & 67 & 5.1 & $3.3-6.8$ & 67 & 3.8 & $2.6-5.0$ \\
\hline Yes to key question(s) highest level & 60 & 1.9 & I.2-2.5 & 28 & 2.0 & $1.0-2.9$ & 32 & 1.8 & $0.9-2.6$ \\
\hline
\end{tabular}

I. The questionnaire enquires about symptoms occurring in the preceding 18 months.

small number of participants from Black and minority ethnic groups.

Participants dependent on cannabis at baseline were at a slightly increased risk of reporting psychotic symptoms at follow-up. Although a precise effect could not be determined owing to the small numbers, our findings are in line with the results of previous population-based longitudinal studies that have linked cannabis use with the onset of psychosis (Arseneault et al, 2002; van Os et al, 2002; Zammit et al, 2002; Fergusson et al, 2003) and provided evidence for a dose-response effect (van Os et al, 2002; Zammit et al, 2002).

A link between urbanicity and psychotic symptoms has been shown in many studies (including van Os et al, 2000, 2001; Sundquist et al, 2004). However, we found that individuals living in rural areas were at increased risk of incident psychotic symptoms. Our measure of urbanicity was based on the interviewer's rating of the area (urban, semi-rural or rural), avoiding the potential for misclassification that may occur when measures of population density are used in areas of substantial heterogeneity. Previous cross-sectional analyses of the British National Psychiatric Morbidity Survey found that urban residence 
Table 3 Univariable predictors of incident self-reported psychotic symptoms

\begin{tabular}{|c|c|c|c|}
\hline Variable & $n$ & OR & $95 \% \mathrm{Cl}$ \\
\hline \multicolumn{4}{|l|}{ Age, years } \\
\hline $16-24$ & 131 & 1.00 & \\
\hline $25-34$ & 352 & 1.53 & $0.63-3.74$ \\
\hline $35-44$ & 378 & 1.46 & $0.60-3.57$ \\
\hline $45-64$ & 674 & 1.05 & $0.41-2.70$ \\
\hline$\geqslant 65$ & 260 & 0.73 & $0.22-2.40$ \\
\hline \multicolumn{4}{|l|}{ Gender } \\
\hline Male & 754 & 1.00 & \\
\hline Female & $104 \mid$ & 0.74 & $0.46-1.19$ \\
\hline $\begin{array}{l}\text { CIS-R score (per unit } \\
\text { increase) }\end{array}$ & 1795 & 1.07 & $1.05-1.10$ \\
\hline \multicolumn{4}{|l|}{ Marital status } \\
\hline Married & 958 & 1.00 & \\
\hline Cohabiting & 168 & 2.46 & $1.19-5.10$ \\
\hline Single & 284 & 1.06 & $0.56-2.01$ \\
\hline Widowed & 133 & 1.19 & $0.37-3.80$ \\
\hline Divorced & 186 & 1.29 & $0.47-3.50$ \\
\hline Separated & 66 & 2.18 & $0.7 \mathrm{I}-6.72$ \\
\hline $\begin{array}{l}\text { IQ score (per I0-unit } \\
\text { increase) }\end{array}$ & 1795 & 0.88 & $0.69-1.11$ \\
\hline \multicolumn{4}{|l|}{ Area type } \\
\hline Urban & 1153 & 1.00 & \\
\hline Semi-rural & 453 & 1.38 & $0.68-2.80$ \\
\hline Rural & 189 & 2.34 & $1.08-5.04$ \\
\hline \multicolumn{4}{|c|}{ Size of primary support group } \\
\hline$\geqslant 9$ & 1126 & 1.00 & \\
\hline $4-8$ & 569 & 1.61 & $0.94-2.78$ \\
\hline $0-3$ & 100 & 4.88 & $1.71-13.9$ \\
\hline \multicolumn{4}{|l|}{ Number of life events } \\
\hline 0 or I & 216 & 1.00 & \\
\hline 2 & 301 & 3.27 & $1.04-10.3$ \\
\hline 3 & 331 & 6.30 & $1.90-20.9$ \\
\hline 4 & 299 & 10.3 & $3.44-31.0$ \\
\hline 5 & 243 & 4.04 & I.14-14.4 \\
\hline$\geqslant 6$ & 405 & 9.25 & $3.39-25.3$ \\
\hline \multicolumn{4}{|l|}{ Current smoker } \\
\hline No & 1265 & 1.00 & \\
\hline Yes & 530 & 2.14 & $1.28-3.57$ \\
\hline \multicolumn{4}{|l|}{ AUDIT score' } \\
\hline $0-7$ & 1332 & 1.00 & \\
\hline $8-15$ & 387 & 1.06 & $0.60-1.88$ \\
\hline $16-40$ & 76 & 3.31 & I.52-7.22 \\
\hline \multicolumn{4}{|l|}{ Cannabis use } \\
\hline $\begin{array}{l}\text { Not used in year prior } \\
\text { to baseline }\end{array}$ & 1629 & 1.00 & \\
\hline $\begin{array}{l}\text { Used in year prior to } \\
\text { baseline but not } \\
\text { dependent }\end{array}$ & 109 & 1.09 & $0.47-2.54$ \\
\hline
\end{tabular}

(continued)
Table 3 (continued)

\begin{tabular}{lll}
\hline Variable & $n \quad$ OR $\quad 95 \% \mathrm{Cl}$ \\
\hline
\end{tabular}

$\begin{array}{llll}\text { Dependent on cannabis } 57 \quad 3.40 & \mathbf{1} .50-7.73\end{array}$

Educational qualifications

$\begin{array}{llll}\text { Degree } & 304 & 1.00 \\ \text { Teaching, HND, nursing } & 168 & 0.98 & 0.2 \mathrm{I}-4.66 \\ \text { A level } & 227 & 0.55 & 0.23-1.32 \\ \text { GCSE or equivalent } & 62 \mathrm{I} & \mathrm{I} .24 & 0.57-2.69 \\ \text { No qualification } & 475 & 0.95 & 0.43-2.08\end{array}$

Employment status

$\begin{array}{lrlll}\text { Working full-time } & 797 & 1.00 \\ \text { Working part-time } & 342 & 0.53 & 0.25-1.09 \\ \text { Unemployed } & 40 & 1.66 & 0.47-5.79 \\ \text { Long-term sick or } & I 4 I & 1.38 & 0.68-2.82 \\ \text { disabled } & & & \\ \text { Other economically } & 475 & 0.75 & 0.40-1.40 \\ \text { inactive } & & & \\ \text { Social class } & & & \\ \text { I } & 102 & 1.00 \\ \text { II } & 605 & 2.19 & 0.82-5.86 \\ \text { III non-manual } & 440 & 1.94 & 0.80-4.7 I \\ \text { III manual } & 329 & 1.69 & 0.66-4.34 \\ \text { IV } & 228 & 3.27 & 1.23-8.67 \\ \text { V } & 9 I & 2.08 & 0.62-6.97\end{array}$

Accommodation tenure

$\begin{array}{lllll}\text { Owned outright } & 447 & \mathrm{I} .00 \\ \text { Owned with mortgage } & 890 & \mathrm{I} .49 & 0.63-3.5 \mathrm{I} \\ \text { Rented from LA or HA } & 336 & 2.38 & 0.94-6.07 \\ \text { Rented from other } & 122 & \mathrm{I} .69 & 0.55-5.22 \\ \text { source } & & & \end{array}$

Gross weekly income

$\begin{array}{llll}\geqslant £ 400 & 379 & 1.00 \\ £ 200 \text { to } £ 399 & 497 & 0.71 & 0.33-1.54 \\ £ 100 \text { to } £ 199 & 459 & 0.59 & 0.26-1.36 \\ <£ 100 & 460 & 0.92 & 0.44-I .91\end{array}$

AUDIT, Alcohol Use Disorders Identification Test; CISR, Clinical Interview Schedule - Revised; GCSE, General Certificate of Secondary Education; HA, housing association; HND, Higher National Dipolma; LA, local authority; OR, odds ratio.

I. AUDIT score $\geqslant 8$ hazardous drinking (Saunders et al, 1993); score $\geqslant 16$ harmful drinking (Singleton et al, 1998).

was, in univariable analysis, weakly associated with self-reported psychotic symptoms but was not significantly associated on multivariable analysis (Johns et al, 2004). We acknowledge that the direction of this association was unexpected and requires further investigation. Indeed, there may be 'critical periods' during which exposure to particular factors (such as area of residence) may be most relevant. Thus differences in the timing of exposure (e.g. current place of residence rather than place of upbringing or birth) may account for the discrepancy. In order to formally test the hypothesis that different risk factors operate at different times we would need to examine the interaction between age and individual risk factors, but in the context of such a rare outcome it is not appropriate to conduct such tests as they would be severely underpowered (and hence the likelihood of a type II error is high).

The role of smoking also remains unclear. Over $80 \%$ of individuals with schizophrenia claim to have started smoking before the onset of their disease (Beratis et al, 2001). A positive association between smoking and schizophrenia has been found in crude analysis (Zammit et al, 2003; Weiser et al, 2004), but after adjustment for confounders, smokers had a reduced risk of developing schizophrenia in one study (Zammit et al, 2003), and an increased risk in the other (Weiser et al, 2004). This may reflect differences in the duration of follow-up or more limited adjustment for confounders in the latter study. In our study, smokers had a $70 \%$ greater risk of incident psychotic symptoms. This may be causal or may reflect self-medication by those in the prodrome, but it was not possible to stratify on time to occurrence of psychotic symptoms (Zammit et al, 2003) to exclude the latter possibility.

The finding that a small primary support group (few close friends or relatives) was associated with a greater likelihood of reporting incident psychotic symptoms was interesting. It is plausible that social isolation might contribute to the development of negative schemas in these individuals and thus play a part in the development of psychotic symptoms (Garety et al, 2001).

Our analysis provided little evidence that marital status, educational qualifications, employment status or income were risk factors for incident psychotic symptoms. Although such factors are important in the aetiology of psychotic disorder, there is an absence of longitudinal data on the role of such factors in the aetiology of psychotic symptoms. The results of our study suggest that there may be some continuity in the risk factors for psychosis and selfreported psychotic symptoms, but - importantly - there may be differences.

There was a strong association between baseline CIS-R score (neurotic symptoms) and incident psychotic symptoms. This concurs with the literature on schizophrenia 
Table 4 Multivariable predictors of incident self-reported psychotic symptoms

\begin{tabular}{|c|c|c|c|c|c|}
\hline \multirow[t]{2}{*}{ Variable } & \multirow[t]{2}{*}{$n$} & \multicolumn{2}{|c|}{ Multivariable predictors } & \multirow{2}{*}{\multicolumn{2}{|c|}{$\begin{array}{l}\text { Adjusted for cannabis use, } \\
\text { IQ score and marital status }\end{array}$}} \\
\hline & & & & & \\
\hline & & $\mathrm{OR}^{\prime}$ & $95 \% \mathrm{Cl}$ & $\mathrm{OR}^{\prime}$ & $95 \% \mathrm{Cl}$ \\
\hline \multicolumn{6}{|l|}{ Area type } \\
\hline Urban & 1153 & 1.00 & & 1.00 & \\
\hline Semi-rural & 453 & 1.67 & $0.82-3.40$ & 1.75 & $0.84-3.66$ \\
\hline Rural & 189 & 3.24 & I.43-7.35 & 3.45 & I.52-7.80 \\
\hline \multicolumn{6}{|l|}{ Size of primary support group } \\
\hline$\geqslant 9$ & 1126 & 1.00 & & 1.00 & \\
\hline $4-8$ & 569 & 1.41 & $0.83-2.38$ & 1.40 & $0.83-2.36$ \\
\hline $0-3$ & 100 & 3.48 & $1.08-11.3$ & 3.43 & $1.10-10.7$ \\
\hline \multicolumn{6}{|l|}{ Number of life events } \\
\hline 0 or I & 216 & 1.00 & & 1.00 & \\
\hline 2 & 301 & 3.51 & $1.12-11.0$ & 3.57 & I.II-II.4 \\
\hline 3 & 331 & 7.72 & $2.21-26.9$ & 7.79 & $2.19-27.7$ \\
\hline 4 & 299 & 11.7 & $3.66-37.1$ & 11.8 & $3.66-38.0$ \\
\hline 5 & 243 & 4.14 & $1.12-15.3$ & 3.92 & $1.01-15.1$ \\
\hline$\geqslant 6$ & 405 & 6.85 & $2.38-19.8$ & 6.45 & $2.17-19.2$ \\
\hline \multicolumn{6}{|l|}{ Current smoker } \\
\hline No & 1265 & 1.00 & & 1.00 & \\
\hline Yes & 530 & 1.89 & $1.13-3.17$ & 1.67 & $0.93-3.01$ \\
\hline \multicolumn{6}{|l|}{ AUDIT score ${ }^{2}$} \\
\hline $0-7$ & 1332 & 1.00 & & 1.00 & \\
\hline $8-15$ & 387 & 0.89 & $0.47-1.7 \mid$ & 0.89 & $0.48-1.68$ \\
\hline $16-40$ & 76 & 2.35 & $1.04-5.31$ & 2.21 & $0.92-5.34$ \\
\hline \multicolumn{6}{|l|}{ Age, years } \\
\hline $16-24$ & $|3|$ & 1.00 & & 1.00 & \\
\hline $25-34$ & 352 & 1.14 & $0.47-2.74$ & 1.24 & $0.52-2.99$ \\
\hline $35-44$ & 378 & 0.96 & $0.36-2.54$ & 1.21 & $0.4 \mathrm{I}-3.52$ \\
\hline $45-64$ & 674 & 0.73 & $0.27-1.98$ & 0.96 & $0.28-3.25$ \\
\hline$\geqslant 65$ & 260 & 0.54 & $0.13-2.14$ & 0.67 & $0.16-2.76$ \\
\hline \multicolumn{6}{|l|}{ Gender } \\
\hline Male & 754 & 1.00 & & 1.00 & \\
\hline Female & 1041 & 0.69 & $0.39-1.24$ & 0.69 & $0.38-1.27$ \\
\hline CIS-R score (per unit increase) & 1795 & 1.07 & $1.04-1.09$ & 1.07 & $1.04-1.09$ \\
\hline \multicolumn{6}{|l|}{ Cannabis use } \\
\hline Not used in year prior to baseline & 1629 & & & 1.00 & \\
\hline $\begin{array}{l}\text { Used in year prior to baseline but } \\
\text { not dependent }\end{array}$ & 109 & & & 0.72 & $0.30-1.75$ \\
\hline Dependent on cannabis & 57 & & & 1.47 & $0.55-3.94$ \\
\hline IQ score (per 10-unit increase) & 1795 & & & 0.88 & $0.65-1.18$ \\
\hline \multicolumn{6}{|l|}{ Marital status } \\
\hline Married & 958 & & & 1.00 & \\
\hline Cohabiting & 168 & & & 1.77 & $0.79-3.94$ \\
\hline Single & 284 & & & 1.08 & $0.53-2.20$ \\
\hline Widowed & 133 & & & 1.47 & $0.42-5.19$ \\
\hline Divorced & 186 & & & 0.78 & $0.25-2.40$ \\
\hline Separated & 66 & & & 1.88 & $0.57-6.19$ \\
\hline
\end{tabular}

AUDIT, Alcohol Use Disorders Identification Test; CIS-R, Clinical Interview Schedule - Revised; OR, odds ratio.

I. Adjusted for psychotropic drugs and therapy.

2. AUDIT score $\geqslant 8$ hazardous drinking (Saunders et al, 1993); score $\geqslant 16$ harmful drinking (Singleton et al, 1998). where, in Swedish conscripts, neurosis has been linked with later schizophrenia, with the evidence suggesting that this may be a prodromal phase of the disease (Lewis et al, 2000). In contrast, although longitudinal population studies have linked low IQ score with psychotic disorder (David et al, 1997; Zammit et al, 2004), the association between IQ score and incident psychotic symptoms within this study was inconclusive. A 10-point increase in IQ score was associated with a $12 \%$ decrease $(\mathrm{OR}=0.88)$ in the risk of incident psychotic symptoms, but the confidence limits were wide.

\section{Strengths and limitations of the study}

This nationally representative population sample has permitted us to examine the incidence of self-reported psychotic symptoms. Furthermore, the longitudinal design permitted us to examine a number of potential aetiological risk factors and - given the exclusion of those with prevalent symptoms at baseline from the denominator - to (tentatively) suggest causality. In crosssectional studies it has not been possible to disentangle risk factors for symptom onset from those for chronicity. However, the possibility that some factors (e.g. adverse life events and alcohol or drug use) may reflect premorbid personality cannot be ruled out. Only a longitudinal study with multiple repeated measures of psychotic symptoms and risk factors over many years from adolescence into adulthood could help exclude such a possibility. To date, no such work has been conducted.

There are a number of limitations. The PSQ was designed as a screening tool for psychotic disorder. The use of lay interviewers broadens the definition and lowers the threshold for recognition, and thus increases prevalence above that ascertained by clinical interview. However, individuals endorsing items on the PSQ are similar to those identified as having psychosis by clinical interview (Bebbington \& Nayani, 1995), suggesting that people with psychosis may emerge from the pool of those with minor psychotic-like experiences and beliefs. It has been suggested that the major difference is the level of preoccupation, distress and disability in those with psychotic illness. Endorsement of key questions in the PSQ probably identified psychotic-like experiences and beliefs in some people who are relatively untroubled 
by them, but also in some who are on the edge of diagnosable psychosis. We cannot exclude the possibility that, in some individuals, the psychotic symptoms might have occurred during periods of intoxication (illicit drugs or alcohol) and that others might have reported hallucinations occurring during physical illness.

Finally, given the low incidence of psychotic symptoms, the study may be underpowered to detect associations, particularly with rare exposures. This is reflected in the wide confidence intervals surrounding a number of the effect estimates. For this reason we are not able to examine risk factors for persistent psychotic symptoms in this data-set.

\section{Future research}

The epidemiology of psychotic symptoms has some similarities with the epidemiology of schizophrenia, but there are also some striking differences. Further understanding of these differences might help to explain the relationship between early stages of psychosis and disabling psychotic illnesses.

\section{ACKNOWLEDGEMENTS}

We thank the Office for National Statistics staff who were involved in the fieldwork and data preparation of the National Psychiatric Morbidity Survey.We also thank Professor Robin Murray for his comments on an earlier draft of this manuscript. Data collection was funded by the Department of Health and the Scottish Executive Health Department. However, the views expressed in this paper are those of the authors alone and not necessarily those of the Department of Health or the Scottish Executive.

\section{REFERENCES}

Arsenault, L., Cannon, M., Poulton, R., et al (2002) Cannabis use in adolescence and risk for adult psychosis: longitudinal prospective study. BMJ, 325, 1212-1213

Bebbington, P. \& Nayani, T. (1995) The psychosis screening questionnaire. International Journal of Methods in Psychiatric Research, 5, II-19.

Beratis, S., Katrivanou, A. \& Gourzis, P. (200I)

Factors affecting smoking in schizophrenia.

Comprehensive Psychiatry, 42, 393-402.

Brugha, T. S., Sturt, E., MacCarthy, B., et al (1987) The Interview Measure of Social Relationships: the description and evaluation of a survey instrument for assessing personal social resources. Social Psychiatry, 22, $123-128$

Brugha, T. S., Wing, J. K., Brewin, C. R., et al (1993)

The relationship of social network deficits with deficits in social functioning in long-term psychiatric disorders. Social Psychiatry and Psychiatric Epidemiology, 28, 218-224.

Brugha, T. S., Bebbington, P. E. \& Jenkins, R. (1999) A difference that matters: comparisons of structured

\section{CLINICAL IMPLICATIONS}

- People who smoke, those living in a rural area, individuals with little social support, those experiencing adverse life events, those with neurotic symptoms and individuals who drink alcohol excessively have an increased risk of experiencing psychotic symptoms.

- The risk factors for psychotic symptoms showed some similarities with risk factors for schizophrenia, but there were also striking differences.

- Further understanding of these differences might help to explain the relationship between early stages of psychosis and disabling psychotic illnesses.

\section{LIMITATIONS}

Psychotic symptoms were based on self-report rather than clinical interview.

- Given the low incidence of psychotic symptoms, the study may have been underpowered to detect associations with rare exposures.

- We were unable to examine risk factors for persistent psychotic symptoms, again owing to their low incidence.

NICOLA J.WILES, PhD, Academic Unit of Psychiatry, Department of Community Based Medicine, University of Bristol; STANLEY ZAMMIT, PhD, Division of Psychological Medicine, Cardiff University; PAUL BEBBINGTON, $\mathrm{PhD}$, Department of Mental Health Sciences, Royal Free and University College Medical School, University College London; NICOLA SINGLETON, MSc, Drugs and Alcohol Research Programme, Research Development \& Statistics Directorate, Home Office, London; HOWARD MELTZER, PhD, Office for National Statistics, London; GLYN LEWIS, PhD, Academic Unit of Psychiatry, Department of Community Based Medicine, University of Bristol, UK

Correspondence: Dr Nicola J.Wiles, Academic Unit of Psychiatry, Department of Community Based Medicine, University of Bristol, The Grange, I Woodland Road, Bristol BS8 IAU, UK. Tel: +44 (0) II7 954 6676; fax: +(0)117 331 0964; e-mail: nicola.wiles@bristol.ac.uk

(First received I3 April 2005, final revision 29 September 2005, accepted 27 October 2005)

and semi-structured psychiatric diagnostic interviews in the general population. Psychological Medicine, 29, $1013-1020$

David, A. S., Malmberg, A., Brandt, L., et al (1997) $\mathrm{IQ}$ and risk for schizophrenia: a population-based cohort study. Psychological Medicine, 27, I3II-1323.

Eaton, W. W., Romanoski, A., Anthony, J. C., et al (1991) Screening for psychosis in the general population with a self-report interview. Journal of Nervous and Mental Disease, 179, 689-693.

Fergusson, D. M., Horwood, L. J. \& Swain-Campbell, N. R. (2003) Cannabis dependence and psychotic symptoms in young people. Psychological Medicine, 33. |5-2|.

Garety, P. A., Kuipers, E., Fowler, D., et al (2001) A cognitive model of the positive symptoms of psychosis. Psychological Medicine, 3I, I89-195.

Hosmer, D. W. J. \& Lemeshow, S. (1989) Applied Logistic Regression. New York: Wiley.

Janssen, I., Hanssen, M., Bak, M., et al (2003) Discrimination and delusional ideation. British Journal of Psychiatry, 182, 7I-76.
Johns, L. C., Nazroo, J.Y., Bebbington, P., et al (2002) Occurrence of hallucinatory experiences in a community sample and ethnic variations. British Journal of Psychiatry, 180, 174-178.

Johns, L. C., Cannon, M., Singleton, N., et al (2004) Prevalence and correlates of self-reported psychotic symptoms in the British population. British Journal of Psychiatry, 185, 298-305.

King, M., Nazroo, J.Y., Weich, S., et al (2005) Psychotic symptoms in the general population of England. A comparison of ethnic groups (the EMPIRIC study). Social Psychiatry and Psychiatric Epidemiology, 40, 375-381.

Lewis, G. (1994) Assessing psychiatric disorder with a human interviewer or a computer. Journal of Epidemiology and Community Health, 48, 207-210.

Lewis, G., Pelosi, A. J., Araya, R., et al (1992) Measuring psychiatric disorder in the community: a standardized assessment for use by lay interviewers. Psychological Medicine, 22, 465-486.

Lewis, G., David, A. S., Malmberg, A., et al (2000) Non-psychotic psychiatric disorder and subsequent risk 
of schizophrenia: cohort study. British Journal of Psychiatry, 177, 416-420.

Meltzer, H., Gill, B., Petticrew, M., et al (1994) OPCS Surveys of Psychiatric Morbidity in Great Britain, Report I: The Prevalence of Psychiatric Morbidity Among Adults Living in Private Households. London: HMSO.

Nelson, H. E. (1982) National Adult Reading Test. Windsor: NFER-Nelson

Office for Population Censuses and Surveys (1991) Standard Occupational Classification. London: HMSO.

Olfson, M., Lewis-Fernandez, R., Weissman, M. M., et al (2002) Psychotic symptoms in an urban general medicine practice. American Journal of Psychiatry, $\mathbf{1 5 9}$ |412-1419.

Rothman, K. J. \& Greenland, S. (1998) Modern Epidemiology. Philadelphia, PA: Lippincott-Raven.

Saunders, J. B., Aasland, O. G., Babor, T. F., et al (1993) Development of the Alcohol Use Disorders Identification Test (AUDIT); WHO collaborative project on early detection of persons with harmful alcohol consumption - II. Addiction, 88, 79I-804.

Singleton, N. \& Lewis, G. (2003) Better or Worse: A Longitudinal Study of the Mental Health of Adults Living in Private Households in Great Britain. London: TSO (The Stationery Office)

Singleton, N., Meltzer, H., Gatward, R., et al (1998) Psychiatric Morbidity Among Prisoners in England and Wales. London: TSO (The Stationery Office).
Singleton, N., Bumpstead, R., O'Brien, M., et a (200I) Psychiatric Morbidity Among Adults Living in Private Households, 2000. London: TSO (The Stationery Office).

Sundquist, K., Frank, G. \& Sundquist, J. (2004) Urbanisation and incidence of psychosis and depression: follow-up study of 4.4 million women and men in Sweden. British Journal of Psychiatry 184, 293-298.

Tien, A.Y. (1991) Distributions of hallucinations in the population. Social Psychiatry and Psychiatric Epidemiology, 26, 287-292.

Van Os, J. \& Verdoux, H. (2002) Diagnosis and classification of schizophrenia: categories versus dimensions, distributions versus disease. In The Epidemiology of Schizophrenia (eds R. Murray, P. B. Jones, E. Susser, et al), pp. 364-4I0. Cambridge: Cambridge University Press.

Van Os, J., Hanssen, M., Bijl, R.V., et al (2000) Strauss (1969) revisited: a psychosis continuum in the general population? Schizophrenia Research, 45, II-20.

Van Os, J., Hanssen, M., Bijl, R. V., et al (200I) Prevalence of psychotic disorder and community level of psychotic symptoms: an urban-rural comparison Archives of General Psychiatry, 58, 663-668.

\section{Van Os, J., Bak, M., Hanssen, M., et al (2002)} Cannabis use and psychosis: a longitudinal populationbased study. American Journal of Epidemiology, 156 319-327.
Verdoux, H., van Os, J., Maurice-Tison, S., et al (1998) Is early adulthood a critical developmental stage for psychosis proneness? A survey of delusional ideation in normal subjects. Schizophrenia Research, 29, 247-254.

Weiser, M., Reichenberg, A., Grotto, I., et al (2004) Higher rates of cigarette smoking in male adolescents before the onset of schizophrenia: a historical prospective cohort study. American Journal of Psychiatry, 161, 1219-1223.

Wing, J. K., Babor, T., Brugha, T., et al (1990) SCAN Schedules for Clinical Assessment in Neuropsychiatry. Archives of General Psychiatry, 47, 589-593.

World Health Organization (1993) The ICD-10 Classification of Mental and Behavioural Disorders. Diagnostic Criteria for Research. Geneva: WHO.

Zammit, S., Allebeck, P., Andreasson, S., et al (2002) Self reported cannabis use as a risk factor for schizophrenia in Swedish conscripts of 1969: historical cohort study. BMJ, 325, I199-1202.

Zammit, S., Allebeck, P., Dalman, C., et al (2003) Investigating the association between cigarette smoking and schizophrenia in a cohort study. American Journal of Psychiatry, 160, 2216-2221.

Zammit, S., Allebeck, P., David, A. S., et al (2004) A longitudinal study of premorbid IQ score and risk of developing schizophrenia, bipolar disorder, severe depression, and other nonaffective psychoses. Archives of General Psychiatry, 6I, 354-360. 